\title{
Snail plays a key role in E-cadherin-preserved esophageal squamous cell carcinoma
}

\author{
SHOJI NATSUGOE, YASUTO UCHIKADO, HIROSHI OKUMURA, MASATAKA MATSUMOTO, \\ TETSURO SETOYAMA, KIYOKAZU TAMOTSU, YOSHIAKI KITA, AKIHIKO SAKAMOTO, \\ TESTUHIRO OWAKI, SUMIYA ISHIGAMI and TAKASHI AIKOU
}

Department of Surgical Oncology, Digestive Surgery, Graduate School of Medicine, Kagoshima University, 8-35-1 Sakuragaoka, Kagoshima 890-8520, Japan

Received November 6, 2006; Accepted December 9, 2006

\begin{abstract}
Snail is a zinc-finger transcription factor that triggers the epithelial-mesenchymal transition (EMT) by directly repressing E-cadherin expression. However, the relationship between E-cadherin and Snail expression remains unclear in esophageal squamous cell carcinoma (ESCC). The purpose of the present study was to evaluate the clinical significance of E-cadherin and Snail expression in ESCC. Immunohistochemistry was used to investigate the expression of E-cadherin and Snail proteins in 194 patients with ESCC. The relationship between expression of these proteins and clinicopathological factors was analyzed, and the usefulness of Snail in disease prognosis was evaluated in relation to E-cadherin expression. E-cadherin expression was preserved in $41.2 \%$ of tumors, and Snail expression was confirmed in $61.7 \%$. Tumors with reduced E-cadherin expression invaded deeper $(\mathrm{P}<0.0001)$, had more lymph node metastasis $(\mathrm{P}<0.0001)$ and had more lymphatic invasion $(\mathrm{P}=0.0011)$ than tumors with preserved expression. Tumors that were positive for Snail expression invaded deeper $(\mathrm{P}=0.0385)$, had more distant lymph node metastasis $(\mathrm{pM})$ $(\mathrm{P}=0.0051)$ and had a more advanced stage $(\mathrm{P}=0.0044)$ than those that were negative for Snail expression. Snail expression was not significantly correlated with reduced E-cadherin expression. Patients with reduced E-cadherin expression or positive Snail expression had poor clinical outcomes. In the preserved E-cadherin group, overall survival rate was better in patients with negative Snail expression than in those with positive Snail expression $(\mathrm{P}=0.035)$. Snail appears to play a key role in preserved E-cadherin expression. Further studies on other molecules in the pathways related to reduced E-cadherin expression in ESCC from the view-point of EMT are necessary.
\end{abstract}

Correspondence to: Dr Shoji Natsugoe, Department of Surgical Oncology, Digestive Surgery, Graduate School of Medicine, Kagoshima University, 8-35-1 Sakuragaoka, Kagoshima 890-8520, Japan

E-mail: natsugoe@m2.kufm.kagoshima-u.ac.jp

Key words: cell adhesion, transcriptional factor, immunohistochemistry, prognosis

\section{Introduction}

E-cadherin is a member of the cadherin family, which is known to play an important role in the regulation of intercellular adhesion in epithelial tissues (1). Because one of the first changes in the metastatic process is a decrease in this adhesion $(2,3)$, it has been postulated that abnormal or reduced Ecadherin expression acts to facilitate tumor invasion and the subsequent formation of metastases. Indeed, E-cadherin expression has been found to be closely associated with tumor invasiveness, dedifferentiation, formation of metastases and prognosis in various human carcinomas (4-8). In esophageal squamous cell carcinoma (ESCC), loss of E-cadherin expression is associated with tumor invasiveness, metastasis and prognosis $(9,10)$.

The change in cancer cell phenotype to increased mortality and invasiveness is reminiscent of the epithelial-mesenchymal transition (EMT) that occurs during embryonic development. Snail is a zinc-finger transcription factor that triggers EMT by directly repressing E-cadherin expression (11). Snail overexpression in different epithelial cells leads to dramatic conversion towards a fibroblastic phenotype at the same time that E-cadherin expression is lost, and invasive and migratory properties are acquired (12). At present, the role of Snail in ESCC has not been elucidated. The purpose of the present study was to examine the clinical significance of Snail expression in ESCC and the correlation between Snail expression and E-cadherin expression in ESCC.

\section{Materials and methods}

Patients and specimens. Subjects were 194 patients with ESCC who underwent esophagectomy with lymph node dissection between 1988 and 1998 at Kagoshima University Hospital, Kagoshima, Japan. The patients, 176 males and 18 females, ranged in age from 36 to 85 years (mean, 63.6 years). None of these patients underwent endoscopic mucosal resection, palliative resection, preoperative chemotherapy or radiotherapy, and none of them had synchronous or metachronous multiple cancer in other organs. Specimens of cancer tissues and adjacent non-cancerous tissue were collected from the patients after informed consent was obtained, in accordance with institutional guidelines. 

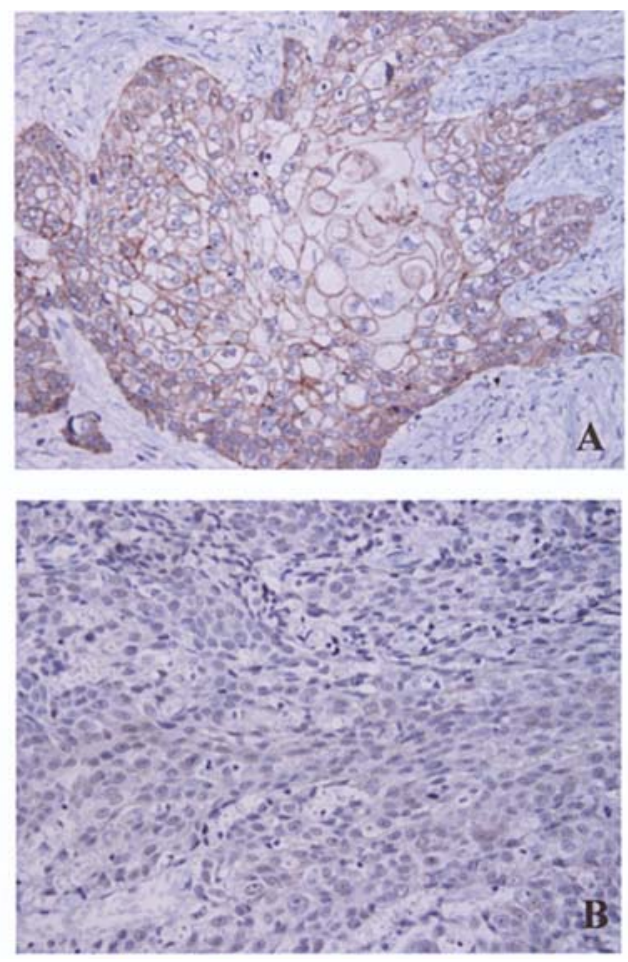
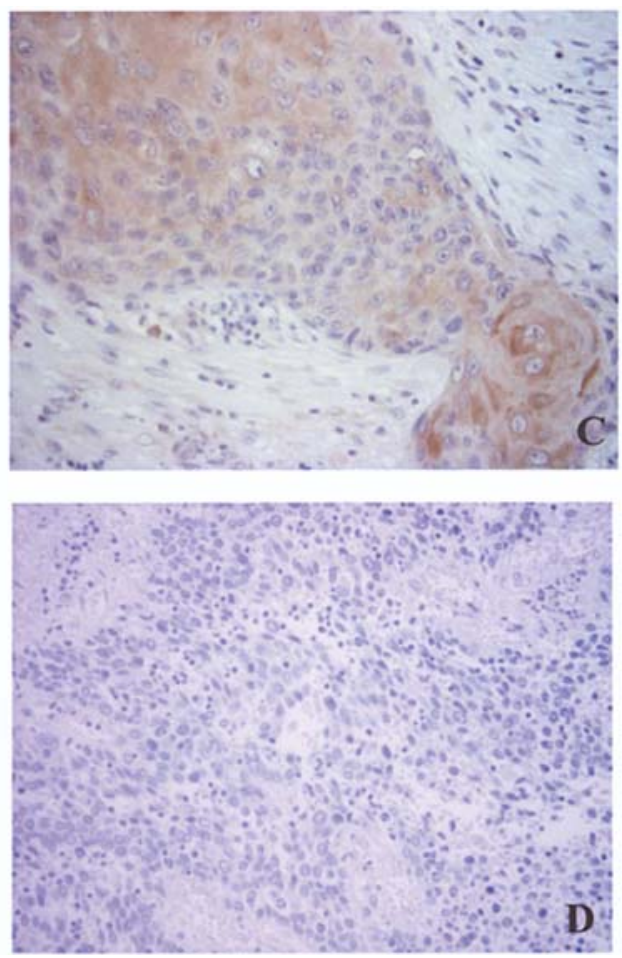

Figure 1. Expression of E-cadherin and Snail in esophageal squamous cell carcinomas. (A) Preserved expression of E-cadherin is detected in the cell membrane (x400). (B) Reduced expression of E-cadherin (x400). (C) Expression of Snail is detected in the cytoplasm (x400). (D) No expression of Snail (x400).

Using the tumor node metastasis (TNM) classification of the International Union against Cancer (13), all of the M1 tumors were attributable to distant lymph node metastases (Table I). All patients were followed-up after discharge, with $\mathrm{X}$-ray examination and tumor marker assays (squamous cell carcinoma antigen and carcinoembryonic antigen) performed every 1-3 months, computed tomography performed every 3-6 months, and ultrasonography performed every 6 months. Bronchoscopic and endoscopic examination was performed when necessary. Postoperative follow-up data were obtained from all patients, with a median follow-up period of 30 months (range, 1-173 months).

Immunohistochemical staining and evaluation. Specimens were cut into $3-\mu \mathrm{m}$ sections, which were mounted on glass slides. Immunohistochemical staining was performed using the streptavidin-biotin peroxidase method as described previously (14). Briefly, after sections were deparaffinized in xylene and dehydrated in ethanol, endogenous peroxidase activity was blocked by incubating sections for $15 \mathrm{~min}$ in $0.3 \% \mathrm{H}_{2} \mathrm{O}_{2}$ in methanol. Sections were then heated in citrate buffer $(0.01 \mathrm{M}, \mathrm{pH} 6.5)$ at $120^{\circ} \mathrm{C}$ for $10 \mathrm{~min}$ (microwave oven, $450 \mathrm{~W}$ ) to reveal antigens. After cooling, sections were preincubated in $3 \%$ skim milk/PBS for $30 \mathrm{~min}$. Sections were then incubated with either anti-E-cadherin monoclonal antibody (1:100; E-cadherin; Takara Biotechnology, Inc., Takara, CA) or anti-Snail polyclonal antibody (1:100; SNAI 1:E-18; Santa Cruz Biotechnology, Inc., Santa Cruz, CA) overnight at $4^{\circ} \mathrm{C}$. Sections were then incubated with biotinylated antigoat IgG and streptavidin-biotin peroxidase [Histofine SAB-PO (G) kit, Nichirei Corp.], and reactions were visualized using diaminobenzidine tetrahydrochloride.
Evaluation of immunohistochemistry was performed by 2 independent investigators (S.N. and Y.U.). Expression of E-cadherin was compared between malignant cells and normal epithelial cells located distant from the tumor. Tumor cells that stained as strongly as normal epithelial cells were considered to have preserved expression, whereas those that exhibited weaker staining patterns than normal epithelial cells or did not stain at all were considered to have reduced expression (15). For Snail, positive expression was defined as detectable immunoreaction in the perinuclear and other cytoplasmic regions in $>10 \%$ of cancer cells. To evaluate expression of Snail and E-cadherin, 10 fields (within the tumor and at the invasive front) were selected, and expression in 1000 tumor cells (100 cells/field) was evaluated at high magnification (x200).

Statistical analysis. Statistical analysis of group differences was performed using the $\chi^{2}$ test and t-test. The Kaplan-Meier method was used for survival analysis, and differences in survival were estimated using the log-rank test. Prognostic factors were examined by univariate and multivariate analyses (Cox proportional hazards regression model). A P-value of $<0.05$ was considered to indicate statistical significance. All statistical analyses were performed using JMP 5 for Windows software (SAS Institute Inc. Cary, NC, USA).

\section{Results}

Expression of E-cadherin and Snail in ESCC. E-cadherin expression was observed on the cell membranes of cancer cells, indicating preserved expression, in $41.2 \%$ of all patients (80 of 194) (Fig. 1A and B). Expression of Snail was observed 
Table I. Relationship between E-cadherin expression and clinicopathological findings.

\begin{tabular}{|c|c|c|c|}
\hline & $\begin{array}{c}\text { E-cad(+) } \\
n=80(41.2 \%)\end{array}$ & $\begin{array}{c}\text { E-cad(-) } \\
\mathrm{n}=114(58.8 \%)\end{array}$ & P-value \\
\hline Age $63.6 \pm 8.2$ & $63.5 \pm 8.2$ & $63.6 \pm 7.8$ & 0.9379 \\
\hline $\begin{array}{l}\text { Gender } \\
\text { (male/female) }\end{array}$ & $72 / 8$ & $104 / 10$ & 0.7716 \\
\hline \multicolumn{4}{|l|}{ Tumor location } \\
\hline Upper & $12(15.0)$ & $14(12.3)$ & 0.7648 \\
\hline Middle & $42(52.5)$ & $58(50.9)$ & \\
\hline Lower & $26(32.5)$ & $42(36.8)$ & \\
\hline \multicolumn{4}{|l|}{ Histology } \\
\hline Well & $28(35.0)$ & $45(39.5)$ & 0.0342 \\
\hline Moderate & $45(56.3)$ & $46(40.3)$ & \\
\hline Poor & $7 \quad(8.7)$ & $23(20.2)$ & \\
\hline \multicolumn{4}{|l|}{$\mathrm{pT}$} \\
\hline $\mathrm{Tl}$ & $33(41.3)$ & 11 (9.6) & 0.0001 \\
\hline $\mathrm{T} 2$ & $9(11.2)$ & $13(11.4)$ & \\
\hline $\mathrm{T} 3$ & $22(27.5)$ & $64(56.1)$ & \\
\hline $\mathrm{T} 4$ & $16(20.0)$ & $26(22.9)$ & \\
\hline \multicolumn{4}{|l|}{$\mathrm{pN}$} \\
\hline pNO & $56(70.0)$ & $28(24.6)$ & 0.0001 \\
\hline $\mathrm{pNl}$ & $24(30.0)$ & $86(75.4)$ & \\
\hline \multicolumn{4}{|l|}{$\mathrm{pM}$} \\
\hline $\mathrm{pM} 0$ & $69(86.3)$ & $69(60.5)$ & $<0.0001$ \\
\hline $\mathrm{pMl}$ & $11(13.8)$ & $45(39.5)$ & \\
\hline \multicolumn{4}{|l|}{ Stage } \\
\hline 1 & $28(12.4)$ & $7(38.8)$ & 0.0001 \\
\hline $2 \mathrm{~A}$ & $22(22.0)$ & $17 \quad(9.4)$ & \\
\hline $2 \mathrm{~B}$ & $6 \quad(9.5)$ & $7(16.5)$ & \\
\hline 3 & $13(24.8)$ & $38(20.0)$ & \\
\hline 4 & $11(31.4)$ & $45(15.3)$ & \\
\hline \multicolumn{4}{|l|}{$\begin{array}{l}\text { Lymphatic } \\
\text { invasion }\end{array}$} \\
\hline Negative & $44(55.0)$ & $36(31.6)$ & 0.0011 \\
\hline Positive & $36(45.0)$ & $78(68.4)$ & \\
\hline \multicolumn{4}{|l|}{$\begin{array}{l}\text { Venous } \\
\text { invasion }\end{array}$} \\
\hline Negative & $58(72.5)$ & $73(64.0)$ & 0.2152 \\
\hline Positive & $22(27.5)$ & $41(36.0)$ & \\
\hline
\end{tabular}

in the cytoplasm of cancer cells in $61.7 \%$ of all patients (84 of 194) (Fig. 1C and D).

Relationship between E-cadherin and Snail expression and clinicopathological features. E-cadherin expression was significantly associated with the following clinicopathological parameters: depth of tumor invasion, lymph node metastasis, stage and lymphatic invasion (Table I). E-cadherin expression
Table II. Relationship between Snail expression and clinicopathological findings.

\begin{tabular}{|c|c|c|c|}
\hline & $\begin{array}{c}\text { Snail }(+) \\
\mathrm{n}=84(61.7 \%)\end{array}$ & $\begin{array}{c}\text { Snail(-) } \\
\mathrm{n}=110(38.3 \%)\end{array}$ & P-value \\
\hline Age & $64.3 \pm 7.8$ & $63.1 \pm 8.0$ & 0.2871 \\
\hline $\begin{array}{l}\text { Gender } \\
\text { (male/female) }\end{array}$ & $79 / 5$ & $97 / 13$ & 0.1540 \\
\hline \multicolumn{4}{|l|}{ Tumor location } \\
\hline Upper & $8 \quad(9.5)$ & $18(16.4)$ & 0.6747 \\
\hline Middle & $41(48.8)$ & $59(53.6)$ & \\
\hline Lower & $35(41.7)$ & $33(30.0)$ & \\
\hline \multicolumn{4}{|l|}{ Tumor depth } \\
\hline $\mathrm{Tl}$ & $11(13.1)$ & $33(30.0)$ & 0.0385 \\
\hline $\mathrm{T} 2$ & $9(10.7)$ & $13(11.8)$ & \\
\hline $\mathrm{T} 3$ & $43(51.2)$ & $43(39.1)$ & \\
\hline $\mathrm{T} 4$ & $21(25.0)$ & $21(19.1)$ & \\
\hline \multicolumn{4}{|l|}{ Histology } \\
\hline Well & $41(48.8)$ & $32(29.1)$ & 0.0186 \\
\hline Moderate & $33(39.3)$ & $58(52.7)$ & \\
\hline Poor & $10(11.9)$ & $20(18.2)$ & \\
\hline \multicolumn{4}{|l|}{$\mathrm{pN}$} \\
\hline pNO & $31(36.9)$ & $53(48.2)$ & 0.1162 \\
\hline $\mathrm{pNl}$ & $53(63.1)$ & $57(51.8)$ & \\
\hline \multicolumn{4}{|l|}{ pM } \\
\hline pM0 & $51(60.7)$ & $87(79.1)$ & 0.0051 \\
\hline $\mathrm{pMl}$ & $33(39.3)$ & $23(20.9)$ & \\
\hline \multicolumn{4}{|l|}{ Stage } \\
\hline 1 & $9(10.7)$ & $26(23.6)$ & 0.0044 \\
\hline $2 \mathrm{~A}$ & $15(17.9)$ & $24(21.8)$ & \\
\hline $2 \mathrm{~B}$ & $2(2.4)$ & $11(10.0)$ & \\
\hline 3 & $25(29.8)$ & $26(23.6)$ & \\
\hline 4 & $33(39.2)$ & $23(21.0)$ & \\
\hline \multicolumn{4}{|l|}{$\begin{array}{l}\text { Lymphatic } \\
\text { invasion }\end{array}$} \\
\hline Negative & $30(35.7)$ & $50(45.5)$ & 0.1721 \\
\hline Positive & $54(64.3)$ & $60(54.5)$ & \\
\hline \multicolumn{4}{|l|}{$\begin{array}{l}\text { Venous } \\
\text { invasion }\end{array}$} \\
\hline Negative & $53(63.1)$ & $78(70.9)$ & 0.2495 \\
\hline Positive & $31(36.9)$ & $32(29.1)$ & \\
\hline \multicolumn{4}{|l|}{$\begin{array}{l}\text { E-cad } \\
\text { expression }\end{array}$} \\
\hline Positive & $29(34.5)$ & $51(46.4)$ & 0.0969 \\
\hline Negative & $55(65.5)$ & $59(53.6)$ & \\
\hline
\end{tabular}

was related to histological differentiation $(\mathrm{P}=0.0342)$. Tumors with reduced E-cadherin expression invaded deeper $(\mathrm{P}<0.0001)$, had more lymph node metastasis $(\mathrm{P}<0.0001)$, had more distant 
Table III. Relationship between Snail expression and clinicopathological findings according to E-cadherin expression.

\begin{tabular}{|c|c|c|c|c|c|c|}
\hline & \multicolumn{2}{|c|}{ E-cad(+) } & \multirow[b]{2}{*}{ P-value } & \multicolumn{2}{|c|}{ E-cad(-) } & \multirow[b]{2}{*}{ P-value } \\
\hline & Snail(+) n=29, (\%) & Snail(-) $n=51,(\%)$ & & Snail(+) n=55, (\%) & Snail(-) $\mathrm{n}=59,(\%)$ & \\
\hline \multicolumn{7}{|c|}{ Tumor location } \\
\hline Upper & $1 \quad(3.4)$ & $11(21.6)$ & \multirow[t]{3}{*}{0.0214} & $7(12.7)$ & 7 (11.9) & \multirow[t]{3}{*}{0.9344} \\
\hline Middle & $14(48.3)$ & $28(54.9)$ & & $27(49.1)$ & $31(52.5)$ & \\
\hline Lower & $14(48.3)$ & $12(23.5)$ & & $21(38.2)$ & $21(35.6)$ & \\
\hline \multicolumn{7}{|c|}{ Tumor depth } \\
\hline $\mathrm{Tl}$ & $7(24.1)$ & $26(51.0)$ & \multirow{4}{*}{0.0364} & $4 \quad(7.3)$ & 7 (11.9) & \multirow[t]{4}{*}{0.8451} \\
\hline $\mathrm{T} 2$ & $2(6.9)$ & $7(13.7)$ & & $7(12.7)$ & $6(10.2)$ & \\
\hline $\mathrm{T} 3$ & $12(41.4)$ & $10(19.6)$ & & $31(56.4)$ & $33(55.9)$ & \\
\hline $\mathrm{T} 4$ & $8(27.6)$ & $8(15.7)$ & & $13(23.6)$ & $13(22.0)$ & \\
\hline \multicolumn{7}{|l|}{ Histology } \\
\hline Well & $14(48.3)$ & $14(27.5)$ & \multirow[t]{3}{*}{0.1218} & $27(49.1)$ & $18(30.5)$ & \multirow[t]{3}{*}{0.0628} \\
\hline Moderate & $12(41.1)$ & $33(64.7)$ & & $21(38.2)$ & $25(42.4)$ & \\
\hline Poor & $3(10.3)$ & $4 \quad(7.8)$ & & $7(12.7)$ & $16(27.1)$ & \\
\hline \multicolumn{7}{|l|}{$\mathrm{pN}$} \\
\hline pNO & $18(62.1)$ & $38(74.5)$ & \multirow[t]{2}{*}{0.2431} & $13(23.6)$ & $15(25.4)$ & \multirow[t]{2}{*}{0.8247} \\
\hline $\mathrm{pNl}$ & $11(37.9)$ & $13(25.5)$ & & $42(76.4)$ & $44(74.6)$ & \\
\hline \multicolumn{7}{|l|}{$\mathrm{pM}$} \\
\hline pM0 & $22(75.9)$ & $47(92.2)$ & \multirow[t]{2}{*}{0.0419} & $29(52.7)$ & $40(67.8)$ & \multirow[t]{2}{*}{0.1000} \\
\hline $\mathrm{pMl}$ & $7(24.1)$ & $4 \quad(7.8)$ & & $26(47.3)$ & $19(32.2)$ & \\
\hline \multicolumn{7}{|l|}{ Stage } \\
\hline 1 & $7(24.1)$ & $21(41.3)$ & \multirow[t]{5}{*}{0.0037} & $2(3.6)$ & $5 \quad(8.5)$ & \multirow[t]{5}{*}{0.4246} \\
\hline $2 \mathrm{~A}$ & $8(27.7)$ & $14(27.5)$ & & $7(12.7)$ & $10(16.9)$ & \\
\hline $2 \mathrm{~B}$ & $0 \quad(0)$ & $6(11.7)$ & & $2(3.6)$ & $5 \quad(8.5)$ & \\
\hline 3 & $7(24.1)$ & $6(11.7)$ & & $18(32.8)$ & $20(33.9)$ & \\
\hline 4 & $7(24.1)$ & $4 \quad(7.8)$ & & $26(47.3)$ & $19(32.2)$ & \\
\hline \multicolumn{7}{|l|}{$\begin{array}{l}\text { Lymphatic } \\
\text { invasion }\end{array}$} \\
\hline Negative & $15(51.7)$ & $29(56.9)$ & \multirow[t]{2}{*}{0.6570} & $15(27.3)$ & $21(35.6)$ & \multirow[t]{2}{*}{0.3396} \\
\hline Positive & $14(48.3)$ & $22(43.1)$ & & $40(72.7)$ & $38(64.4)$ & \\
\hline \multicolumn{7}{|c|}{ Venous invasion } \\
\hline Negative & $19(65.5)$ & $39(76.5)$ & \multirow[t]{2}{*}{0.2915} & $34(61.8)$ & $39(66.1)$ & \multirow[t]{2}{*}{0.6339} \\
\hline Positive & $10(34.5)$ & $12(23.5)$ & & $21(38.2)$ & $20(33.9)$ & \\
\hline
\end{tabular}

nodal metastasis $(\mathrm{pM})(\mathrm{P}<0.0001)$ and had more lymphatic invasion $(\mathrm{P}=0.0011)$ than tumors with preserved expression.

Snail expression was related to histological differentiation $(\mathrm{P}=0.0186)$. Tumors that were positive for Snail expression invaded deeper $(\mathrm{P}=0.0385)$, had more distant lymph node metastasis $(\mathrm{pM})(\mathrm{P}=0.0051)$ and had a more advanced stage $(\mathrm{P}=0.0044)$ than those that were negative for Snail expression ( $\mathrm{P}=0.0385,0.0051$ and 0.0044 , respectively) (Table II).

Of the 80 tumors with preserved E-cadherin expression, $29(36.3 \%)$ were positive for Snail expression. On the other hand, 55 tumors $(46.0 \%)$ were positive for Snail expression among the 114 tumors with reduced E-cadherin expression. Significant differences were not found between E-cadherin and Snail expression $(\mathrm{P}=0.0969)$.
Relationship between Snail expression and clinicopathological variables according to E-cadherin expression. Tumors were divided into the preserved E-cadherin group and the reduced E-cadherin group. In the preserved E-cadherin group, expression of Snail was related to depth of tumor invasion, distant lymph node metastasis (pM1), and stage. In the reduced E-cadherin group, expression of Snail was not related to any clinicopathologic factors (Table III).

Relationship between prognosis and expression of E-cadherin and Snail. Seven of the patients died of postoperative complications within 30 days of the beginning of the study period, leaving 187 patients for survival analysis. The 5-year survival rate of patients with tumors with preserved E-cadherin 

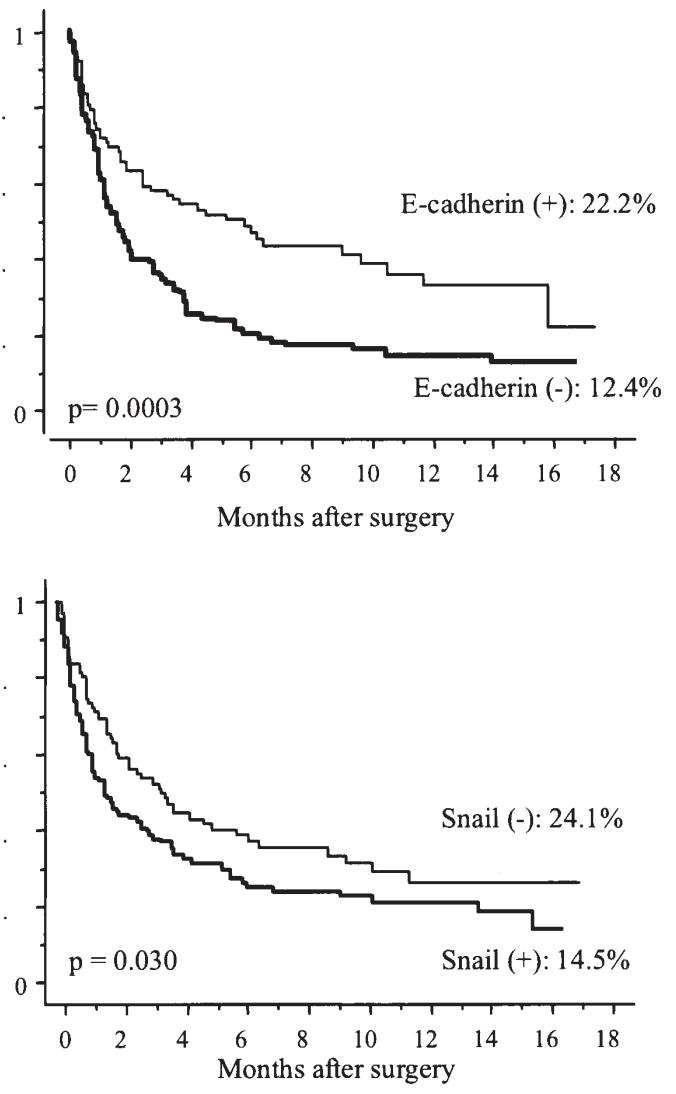

Figure 2. The postoperative overall survival curve of patients according to the expression of E-cadherin (A) or Snail (B). There was a significant difference in survival between the patients with preserved and reduced expression of E-cadherin $(\mathrm{P}=0.003)$. There also was a significant difference in overall survival between the patients with (+) and without (-) expression of Snail $(\mathrm{P}=0.030)$.

expression was $22.2 \%$, whereas the rate for reduced E-cadherin expression was $12.4 \%$. There was a significant difference in 5-year survival between preserved and reduced expression of E-cadherin ( $\mathrm{P}=0.003$; Fig. 2A). The 5-year survival rate of patients negative and positive for expression of Snail was $24.1 \%$ and $14.5 \%$, respectively, and the difference was significant $(\mathrm{P}=0.030)$ (Fig. 2B).

Relationship between prognosis and Snail expression in preserved and reduced E-cadherin groups. In the preserved E-cadherin group, the overall survival rate was significantly higher for patients negative for Snail expression than for those positive for Snail expression ( $\mathrm{P}=0.029$; Fig. 3A). However, in the E-cadherin reduced group, there were no significant differences between patients positive and negative for Snail expression (Fig. 3B).

Univariate and multivariate analyses of survival. Table IV shows the univariate and multivariate analyses of factors related to patient prognosis. Univariate analysis revealed that the following factors were significantly related to postoperative survival: depth of tumor invasion, lymph node metastasis, stage, lymphatic invasion, venous invasion, E-cadherin expression, Snail expression and combination of E-cadherin and Snail expression. Multivariate regression analysis indicated that depth of invasion and lymph node metastasis,
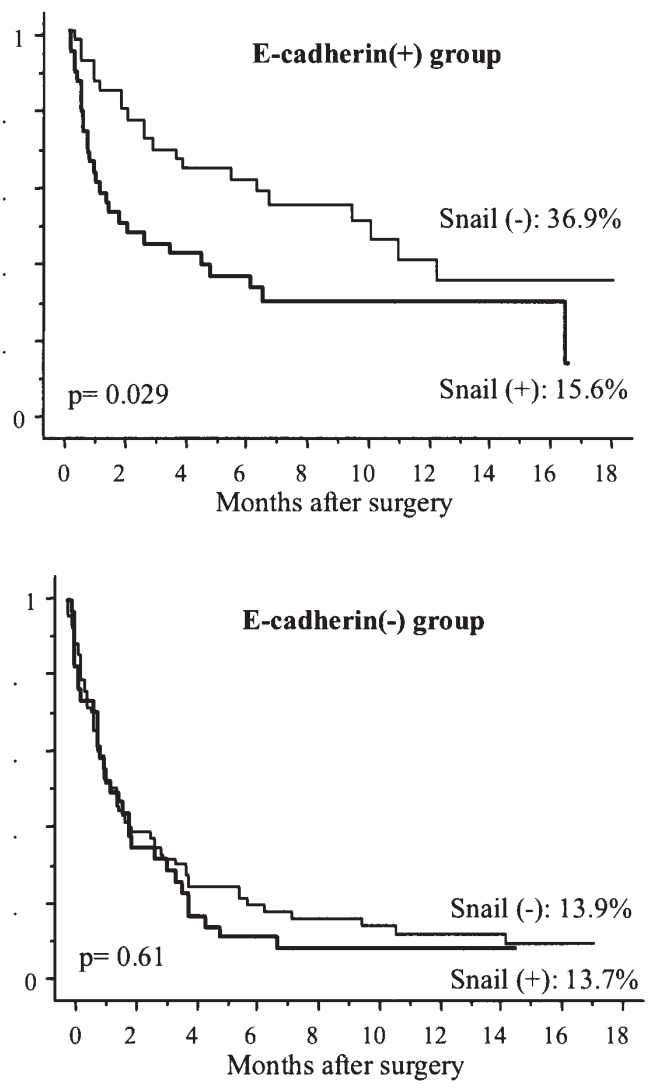

Figure 3. The postoperative survival curves between the patients with (+) and without (-) Snail expression according to E-cadherin expression. (A) In the preserved E-cadherin expression group, the patients without Snail expression (-) had a better outcome than those with Snail expression $(+)(\mathrm{P}=0.029)$. (B) In the reduced E-cadherin expression group, there was no difference between the patients with Snail expression (+) and without Snail expression (-).

stage and venous invasion were independent prognostic factors, but that E-cadherin expression, Snail expression, and combination of E-cadherin and Snail expression were not independent prognostic factors.

\section{Discussion}

Cell-cell adhesion molecules, which are present in tight junctions, intermediate junctions, desmosomes and gap junctions, play an important role both in normal cell structures, and in cancer invasion and metastasis (16). E-cadherin is one such molecule. As E-cadherin expression decreases, the incidence of lymph node metastasis increases, resulting in poor prognosis in various types of cancer, including ESCC (17). The concept of EMT, which is a determinant of carcinoma progression, was recently proposed. Loss of E-cadherin expression is emerging as one of the most common indicators of EMT onset (18). EMT induction by Snail in epithelial cells is mediated by direct transcriptional repression of E-cadherin. We hypothesized that an inverse correlation between Ecadherin and Snail expression is present in ESCC.

In the present study, E-cadherin expression was related to histological differentiation, tumor depth, lymph node metastasis, lymphatic invasion and stage. Positive Snail expression was associated with histology, tumor depth, distant nodal metastasis (pM1) and stage. As Snail expression is 
Table IV. Univariate and multivariate analyses of prognostic factors.

\begin{tabular}{lcccc}
\hline Prognostic factors & Univariate $\mathrm{P}$ & Multivariate $\mathrm{P}$ & Hazard ratio & 95\% confidence interval \\
\hline pT (pTl-2/pT3-4) & $<0.0001$ & 0.0025 & 1.923 & $1.251-2.953$ \\
pN (pN0/pNl) & $<0.0001$ & 0.0003 & 1.849 & $1.184-2.888$ \\
Stage (I,II/III,IV) & $<0.0001$ & 0.0004 & 2.933 & $1.882-4.571$ \\
Venous invasion & $<0.0001$ & 0.0044 & 1.776 & $1.210-2.607$ \\
Lymphatic invasion & $<0.0001$ & 0.1858 & 1.346 & $0.870-2.083$ \\
E-cadherin (preserved/reduced) & 0.0003 & 0.9191 & 1.029 & $0.681-1.553$ \\
Snail (negative/positive) & 0.03 & 0.8103 & 1.047 & $0.662-1.326$ \\
Combination of E-cadherin and Snail & 0.0008 & 0.6228 & 1.133 & $0.713-1.800$
\end{tabular}

(E-cadherin preserved + Snail negative/

other groups)

related to tumor depth in human breast cancer, it is possible that Snail might repress E-cadherin expression during development and tumor progression through interaction with the proximal E-boxes of E-cadherin promoters (19). Inverse correlations between E-cadherin and Snail expression have been found in liver, bladder, pancreas, colon and breast cancer cells $(12,18,20,21)$. In the present study, however, significant correlations were not found between E-cadherin and Snail expression. Molecules other than Snail may affect the loss of E-cadherin expression. Slug is also a zinc-finger transcription factor which is a member of the Snail family. When we previously examined the relationship between E-cadherin and Slug expression in ESCC, a close relationship was found (22). In breast cancer cell lines, expression of Slug, rather than Snail, was strongly correlated with the absence of E-cadherin transcripts (23). Tan et al (24) reported that inhibition of the integrin-linked kinase pathway in colon cancer cells, which suppresses $\beta$-catenin signaling, also repressed Snail promoter activity. Thus, the expression of Snail may be regulated by integrin-linked kinase, and Snail expression is at least one molecular event in the acquisition of more invasive characteristics in ESCC.

In the present study, prognosis was poorer in patients with reduced E-cadherin than in those with preserved expression, which agrees with previous reports. Similarly, the prognosis was worse in patients with Snail expression than in those without Snail expression. However, some patients with preserved E-cadherin expression had a poor prognosis. Thus, we analyzed the data by dividing Snail expression into two groups based on E-cadherin expression. In the preserved Ecadherin group, Snail expression was correlated with tumor depth and stage. Thus, overall survival was poorer in patients with Snail expression than in those without Snail expression. On the other hand, in the reduced E-cadherin group, no significant correlations were seen between Snail expression and clinicopathologic factors, including prognosis. Although the patients with preserved E-cadherin and negative Snail expression had the best clinical outcome according to univariate analysis, it was not an independent prognostic factor on multivariate analysis.

These results, together with our previous reports on Slug expression (22), suggested that the function of Snail varies with E-cadherin expression in ESCC. In tumors with preserved E-cadherin expression, Snail and Slug may play a key role in EMT regulation. In tumors with reduced E-cadherin expression, E-cadherin expression may be regulated not only by Snail and Slug, but also by other transcription factors, such as Twist or Sip1, or genetic/epigenetic alternation (25). In gastric cancer, Rosivatz et al (26) suggested that, in the context of EMT regulation with respect to E-cadherin expression, two different pathways are present in the diffuse or intestinal type. In the former, Twist, mutant E-cadherin and $\mathrm{N}$-cadherin were related to tumor progression, while in the latter, Sip1 was related to tumor progression. Twist, Goosecoid and Snail repress E-cadherin and induce FOXC2; they also enhance cell migration in vitro and metastatic potential in vivo. Further studies are necessary to determine whether these genes regulate individual or overlapping pathways related to EMT and metastasis in ESCC (27).

In conclusion, Snail may play a key role in E-cadherinpreserved ESCC. Because other molecules may be related to tumor progression and metastasis in ESCC, further examination is necessary, particularly in E-cadherin-reduced ESCC.

\section{Acknowledgements}

This study was supported by grants of the Ministry of Education, Science, Sports and Culture, Japan (grant no. 17390373).

\section{References}

1. Takeichi M: Cadherin cell adhesion receptors as a morphogenetic regulator. Science 251: 1451-1455, 1991.

2. Shiozaki H, Oka H, Inoue M, Tamura S and Monden M: Ecadherin mediated adhesion system in cancer cells. Cancer 77 : 1605-1613, 1996.

3. Jiang WG: E-cadherin and its associated protein catenins, cancer invasion and metastasis. Br J Surg 83: 437-446, 1996.

4. Schipper JH, Frixen UH, Behrens J, Unger A, Jahnke K and Birchmeier W: E-cadherin expression in squamous cell carcinoma of head and neck: inverse correlation with tumor dedifferentiation and lymph node metastasis. Cancer Res 51: 6328-6337, 1991.

5. Mayer B, Johnson JP, Leitl F, et al: E-cadherin expression in primary and metastatic gastric cancer: Down-regulation correlates with cellular dedifferentiation and glandular disintegration. Cancer Res 53: 1690-1695, 1993. 
6. Becker KF, Atkinson MJ, Becker I, Nekarda H, Siewert JR and Höfler H: E-cadherin gene mutations provide clues to diffuse type gastric carcinomas. Cancer Res 54: 3845-3852, 1994.

7. Kinsella AR, Green B, Lepts GC, Bowie G and Taylor BA: The role of the cell-cell adhesion molecule E-cadherin in large bowel tumor cell invasion and metastasis. Br J Cancer 67: 904-909, 1993.

8. Yonemura Y, Nojima N, Kaji M, et al: E-cadherin and urokinasetype plasminogen activator tissue status in gastric carcinoma. Cancer 76: 941-953, 1995.

9. Tamura S, Shiozaki H, Miyata M, et al: Decreased E-cadherin expression is associated with haematogenous recurrence and poor prognosis in patients with squamous cell carcinoma of the esophagus. Br J Surg 83: 1608-1614, 1996.

10. Miyata M, Shiozaki H, Kobayashi K, et al: Correlation between expression of E-cadherin and metastases in human esophageal cancer: preliminary report. Nippon Geka Gakkai Zasshi 91: $1761,1990$.

11. Blanco MJ, Moreno-Bueno G, Sarrio D, et al: Correlation of Snail expression with histological grade and lymph node status in breast carcinomas. Oncogene 21: 3241-3246, 2002.

12. Cano A, Perez-Moreno MA, Rodrigo I, et al: The transcription factor snail controls epithelial-mesenchymal transitions by repressing E-cadherin expression. Nat Cell Biol 2: 76-83, 2000.

13. Sobin LH and Fleming ID: TNM classification of malignant tumors, 5th edition. Union Internationale Contre le Cancer and the American Joint Committee on Cancer. Cancer 80: 1803-1804, 1997.

14. Sugimachi K, Aishima S, Taguchi K, et al: The role of overexpression and gene amplification of cyclin D1 in intrahepatic cholangiocarcinoma. J Hepatol 35: 74-79, 2001.

15. Shiozaki H, Tahara H, Oka H, et al: Expression of immunoreactive E-cadherin adhesion molecules in human cancers. Am J Pathol 139: 17-23, 1991.

16. Natsugoe S, Shimada M, Kumanohoso T, et al: Expression of desmoglein I cell adhesion molecule in primary tumors and metastatic lymph nodes of esophageal cancer. Int J Oncol 6: 345-348, 1995
17. Matsumoto M, Natsugoe S, Nakashima S, et al: Clinical significance of lymph node micrometastasis of pNO esophageal carcinoma. Cancer Lett 153: 189-197, 2000.

18. Batlle E, Sancho E, Franci C, et al: The transcription factor snail is a repressor of E-cadherin gene expression in epithelial tumour cells. Nat Cell Biol 2: 84-89, 2000.

19. Martin TA, Goyal A, Watkins G and Jiang WG: Expression of the transcription factors snail, slug, and twist and their clinical significance in human breast cancer. Ann Surg Oncol 12: 488-496, 2005.

20. Jiao W, Miyazaki K and Kitajima Y: Inverse correlation between E-cadherin and Snail expression in hepatocellular carcinoma cell lines in vitro and in vivo. Br J Cancer 86: 98-101, 2002.

21. Sugimachi K, Tanaka S, Kameyama T, et al: Transcriptional repressor snail and progression of human hepatocellular carcinoma. Clin Cancer Res 9: 2657-2664, 2003.

22. Uchikado Y, Natsugoe S, Okumura H, et al: Slug expression in the E-cadherin preserved tumors is related to prognosis in patients with esophageal squamous cell carcinoma. Clin Cancer Res 11: 1174-1180, 2005

23. Hajra KM, Chen DY and Fearon ER: The SLUG zinc-finger protein represses E-cadherin in breast cancer. Cancer Res 62: 1613-1618, 2002

24. Tan C, Costello P, Sanghera J, et al: Inhibition of integrin linked kinase (ILK) suppresses beta-catenin-Lef/Tcf-dependent transcription and expression of the E-cadherin repressor, snail, in APC-/- human colon carcinoma cells. Oncogene 20: 133-140, 2001.

25. Vernon AE and La Bonne C: Tumor metastasis: a new twist on epithelial-mesenchymal transitions. Curr Biol 14: R719-R721, 2004.

26. Rosivatz E, Becker I, Specht K, et al: Differential expression of the epithelial-mesenchymal transition regulators snail, SIP1, and twist in gastric cancer. Am J Pathol 161: 1881-1891, 2002.

27. Lee JM, Dedhar S, Kalluri R and Thompson EW: The epithelialmesenchymal transition: new insights in signaling, development and disease. J Cell Biol 172: 973-981, 2006. 